\title{
Structured training volume in early adolescence: a risk factor for femoroacetabular impingement?
}

\author{
Karen Mullins ${ }^{1}$ \\ Michael Hanlon ${ }^{1}$ \\ Patrick Carton ${ }^{1,2}$
1 Department of Sport \& Exercise Science, Waterford Institute of Technology, Ireland
2 The Hip and Groin Clinic, UPMC Whitfield, Waterford, Ireland

\author{
Corresponding author: \\ Karen Mullins \\ Department of Sport \& Exercise Science, \\ Waterford Institute of Technology \\ Cork Rd, Waterford, Ireland \\ E-mail:kmullins@wit.ie
}

\section{Summary}

Introduction: To determine whether athletes undergoing surgical intervention for FAl completed more hours of structured training in adolescence than matched healthy athletes.

Methods: Sixty-seven athletes $(25.53 \pm 4.8$ years $)$ undergoing surgical intervention for symptomatic FAl were asked to recall the number of hours engaged in structured training between the ages of 10-12 and 13-15 years old (FAl group). Results were compared to an age (24.56 \pm 4.5 years), gender and activity level matched control group $(n=71)$ with no history of chronic hip/groin pain or hip stiffness and who were currently engaged in similar levels of training and competition.

Results: The FAl group reported significantly more structured training hours between the ages of 10-12 years than controls $(6.55 \pm 3.1$ versus $5.69 \pm 3.7 \mathrm{hrs} /$ week, $p=0.02$ ) but no differences were observed for training volume between the ages of $13-15$ years $(8.45 \pm 3.4$ vs $8.03 \pm 3.7$ hrs/week, $p=.397$ ).

Conclusion: Higher volumes of structured training in early adolescence are a potential risk factor for the development of symptomatic FAl later in the player pathway.

Level of evidence: IV.
KEY WORDS: adolescents, athletes, femoroacetabular impingement, hip, training load.

\section{Introduction}

Femoroacetabular impingement (FAI) is a cause for major concern among young male athletes, caused by excessive bone growth on the femoral head-neck junction and/or the acetabulum of the pelvis. FAl is characterised by insidious anterior groin pain with gradual loss of hip motion and function ${ }^{1,2}$, often exacerbated by bouts of physical activity ${ }^{3}$. FAI has been previously identified as a risk factor for the early development of osteoarthritis of the hip ${ }^{4-6}$. Surgical treatment to remove the impinging bone (Fig. 1) and repair underlying tissue has been reported as a successful treatment option ${ }^{1,2,7-9}$. While the research regarding diagnosis and treatment has grown substantially over the past 15 years, the aetiology of the condition remains unclear. However, a limited amount of research has explored the concept of increased physical activity during bone growth as a risk factor for the development of a bony deformity which later becomes symptomatic as physical activity intensifies. Two retrospective $\mathrm{e}^{10,11}$ and two prospective ${ }^{12,13}$ studies have been carried out and a common theme emerging from the research shows athletes of 12 years of age or younger appear to be particularly at risk of developing an abnormal bony morphology. Differences in mechanical function among adolescent athletes, compared to non-athletic controls have been reported, with reductions in internal rotation evident as young as 13 , which gradually worsened as the athletes increased in age ${ }^{13}$. This highlights the potential risk for further loss of function and gradual progression to symptomatic FAl later in the player pathway.

One key limitation with existing research is that the linkage between symptomatic FAl and volume of training during adolescence using athletes requiring treatment has not been assessed. This may be of greater practical significance as individuals solely presenting with radiological cam impingement can often present with no symptoms ${ }^{14}$. Existing research has examined the influence of physical activity on development of abnormal bony morphology in asymptomatic cohorts; no research has previously identified the effect of intensity of physical activity on development of symptomatic FAI requiring surgery. The aim 

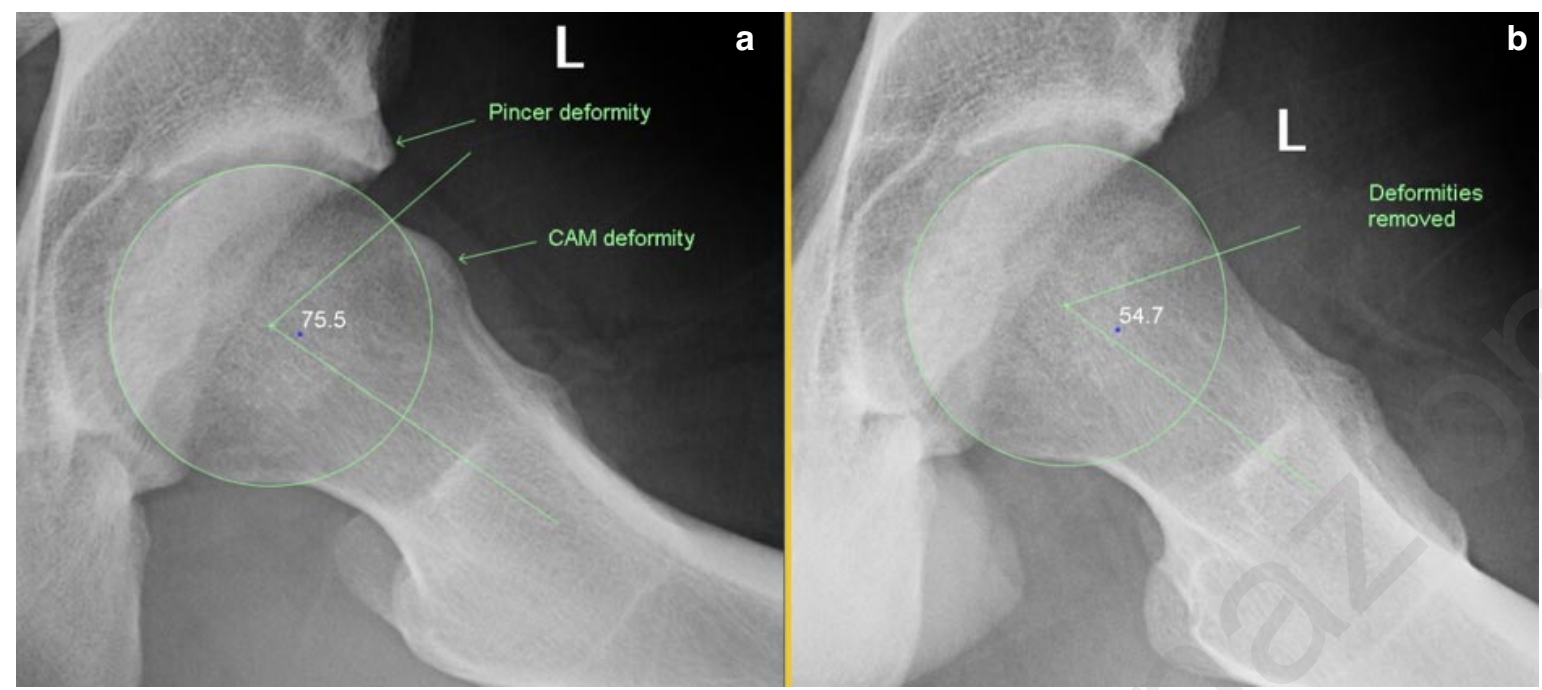

Figure $1 \mathrm{a}$. Alpha angle with bony deformities prior to surgery. b. Alpha angle following surgery with deformities removed.

of this study was, therefore, to examine the volume of structured training volumes undertaken during adolescence in a group of athletes who developed symptomatic FAl and compare this to a matched athletic control group.

\section{Materials and methods}

\section{Recruitment}

Ethical approval for the research was granted by the WIT Research Ethics Committee and adhered to the standard principles of clinical based research ${ }^{15}$. Sixty seven male athletes between the ages of 18-35 undergoing surgical intervention for symptomatic FAI by an experienced orthopaedic surgeon (PC) were recruited. Exclusion criteria included those with a pres- ence of osteoarthritis (OA) on radiograph, a secondary injury other than FAI and prior surgical treatment for the condition (Fig. 2). An age, gender and activity matched control group $(n=71)$ was recruited from local sporting clubs, following the exclusion of those with a history of hip or groin pain/stiffness exacerbated by physical activity, or previous treatment for FAl. Patients presented to the surgeon with symptoms in keeping with FAl; a history of activity-related anterior groin pain/stiffness, a positive FADIR test (flexion, adduction and internal rotation) and decreased levels of adduction and internal rotation (at $90^{\circ}$ flexion). Confirmation of the FAl was determined using standardised $X$-ray evaluation including AP Pelvis, $90^{\circ}$ Dunn and false profile views. Cam impingement was defined by an alpha angle $>55^{\circ}$ (Dunn view) or $>65^{\circ}$ (AP view). Pincer lesions were defined

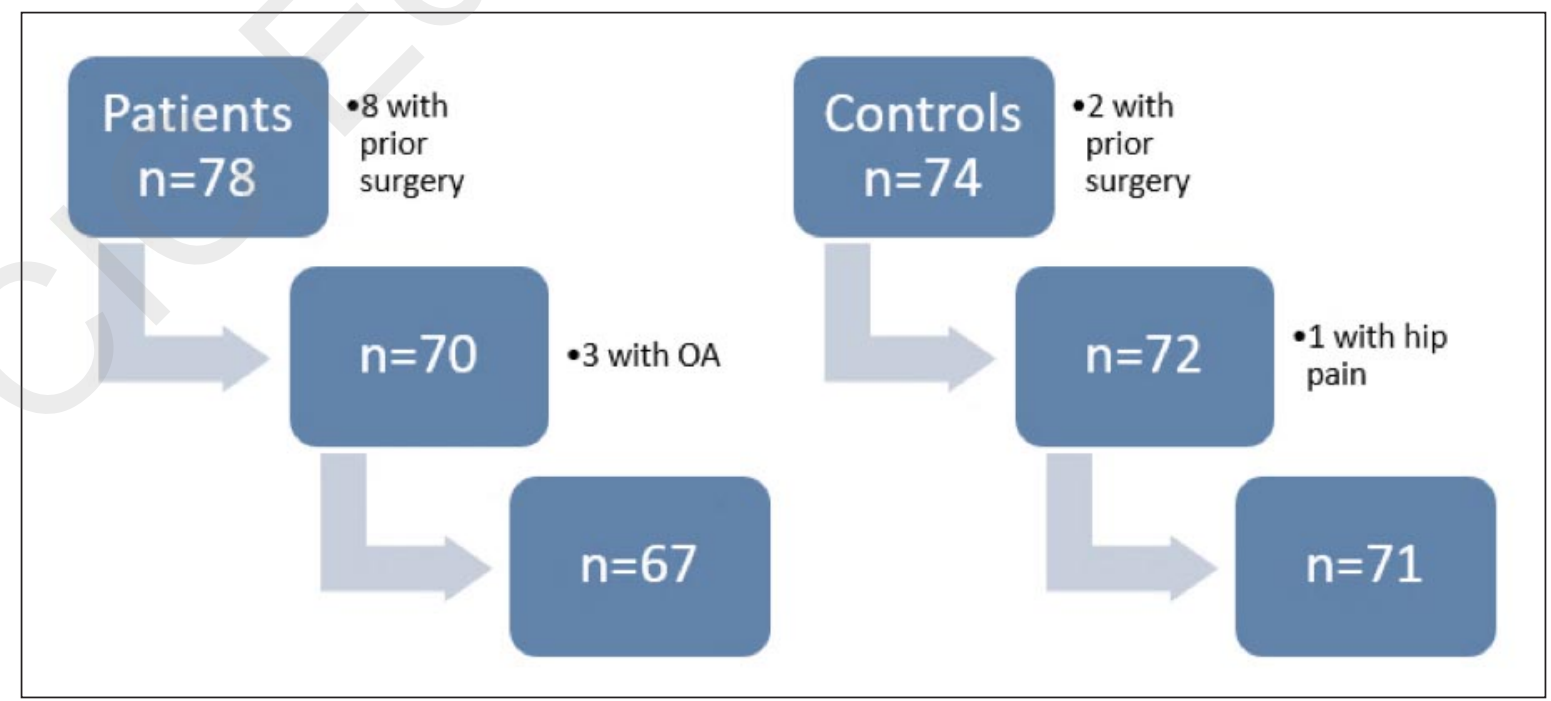

Figure 2. Recruitment of patients and controls. 
with a lateral centre edge angle $>35^{\circ}$, a clear crossover sign on AP view or in the presence of an evident anterolateral rim deformity on false profile view. Combined impingement was diagnosed in the case of a cam lesion on either AP or Dunn view in association with a Pincer lesion on either AP or false profile view. The extent of chondrolabral pathology was determined using MRA scanning and aided in the overall diagnosis of FAI.

\section{Measures}

To increase the accuracy of recall, both groups were first asked to list the different sports played which required structured, organised training between the years of 10-15. They were then asked to quantify the average weekly hours spent engaged in structured training ("structured training" includes both training and competitive matches) for the sports listed at the latter stages of primary school (10-12 age category) and during the early stages of secondary school (1315 age category). This allowed athletes to associate participation with two distinct phases of development and aimed to increase the accuracy of the hours reported. Hip movements were assessed utilising a standardised method to measure the range of passive hip flexion, abduction and internal rotation (at 90 degrees hip flexion). Both hips of each participant were assessed in the supine position with a single operator, using a hand-held goniometer. Two measurements were taken and a mean score was determined for each assessment. The symptomatic limb was utilised in the unilateral patient group and an average score of both asymptomatic limbs was taken for controls and both symptomatic limbs for bilateral patients.

\section{Data analysis}

SPSS version 22 was used for all analysis. All data was firstly assessed for normality using a ShapiroWilk test, an independent samples t-test or MannWhitney $U$ test was then used to determine differences in the average weekly training hours between groups for both age categories. Differences in training volumes between both age categories was assessed using a paired samples t-test. Effect sizes were determined using Cohen's d, using the pooled standard deviation of both groups at each time point. Differences between the groups for ROM was determined using an independent samples t-test or MannWhitney $U$ test. In all cases, $p<0.05$ was considered significant.

\section{Results}

A total of 67 patients and 71 controls were recruited for the study (Tab. I) with no significant differences between the groups with regard to age, body mass or height. The different sports engaged in by both groups at the time of the study are listed in Figure 3. Thirty-six of the patients were diagnosed with unilateral impingement with the remaining 31 having bilateral impingement. There were three cases of isolated cam impingement, 13 patients with pincer impingement only and the remaining patients had combined impingement $(n=51)$. A significant difference $(p=0.020$, effect size $=0.25)$ was found between the patients and controls for the average structured weekly training/competition hours reported in the 1012 age range $(6.55 \pm 3.1$ and $5.69 \pm 3.7 \mathrm{hrs} /$ week for patients and controls, respectively) (Fig. 4). However, there was no significant difference $(p=.397$, effect size $=0.12$ ) observed for training/competition hours between groups for the 13-15 years age range (8.45 \pm 3.4 vs $8.03 \pm 3.7 \mathrm{hrs} /$ week). Both groups reported a significant increase in training hours from the 10-12 to the $13-15$ age range $(p<0.001)$. Finally, the patient group had significantly lower levels of flexion (4\%), abduction $(25 \%)$ and internal rotation $(38 \%)$ compared to the control group (Tab. II).

\section{Discussion}

Femoroacetabular impingement is a chronic, debilitating structural deformity of the hip joint characterised by progressive stiffness, pain and loss of function $3,6,14$. This includes progressive loss of hip ROM as demonstrated in this report, with patients displaying significantly lower levels of hip ROM compared to controls. FAI has been found to be a common issue in young males and females, with those engaged in regular vigorous sporting activity particularly at risk $^{1,2,10-13}$. Previous literature has alluded to heavy involvement in physical activity during skeletal development as a potential risk factor for the development of bony morphologies ${ }^{10-13}$ in particular, cam morphologies. However, the research to date has focused on asymptomatic individuals with bony abnormalities rather than individuals displaying symptomatic FAl. This study is the first to the Author's knowledge to assess the levels of physical activity during adolescence, among athletes who required surgical treatment for FAI, and compare these to a matched

Table I. Participant demographics.

\begin{tabular}{llll}
\hline Group & Age $(\mathbf{y r s})$ & Body mass $\mathbf{( k g )}$ & Height $(\mathbf{c m})$ \\
\hline Patients & $25.53 \pm 4.8$ & $81.5 \pm 9.2$ & $179.3 \pm 5.7$ \\
Controls & $24.56 \pm 4.5$ & $82.9 \pm 7.5$ & $180.2 \pm 6.5$ \\
\hline
\end{tabular}




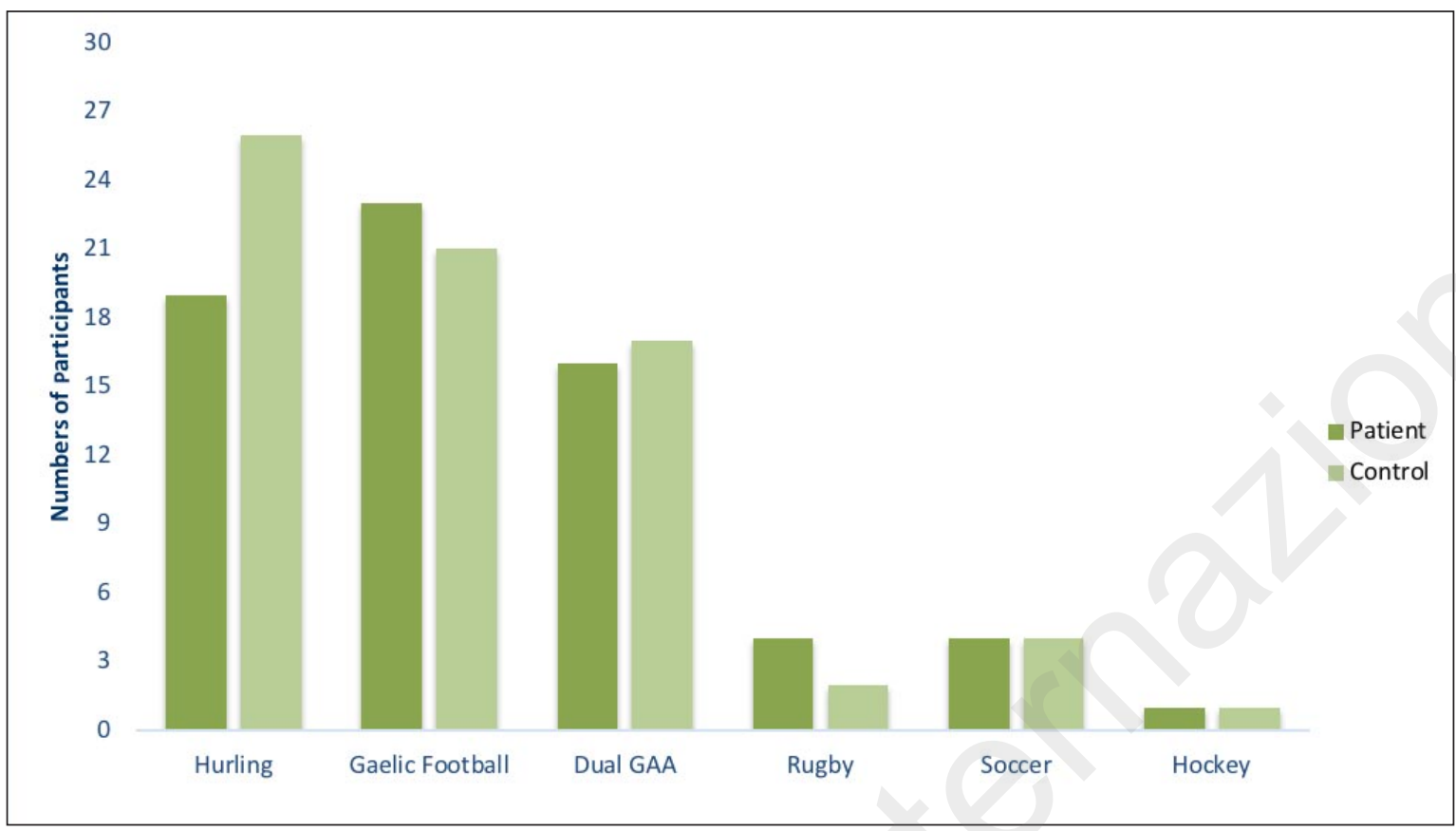

Figure 3. Sports engaged in by patients and controls.

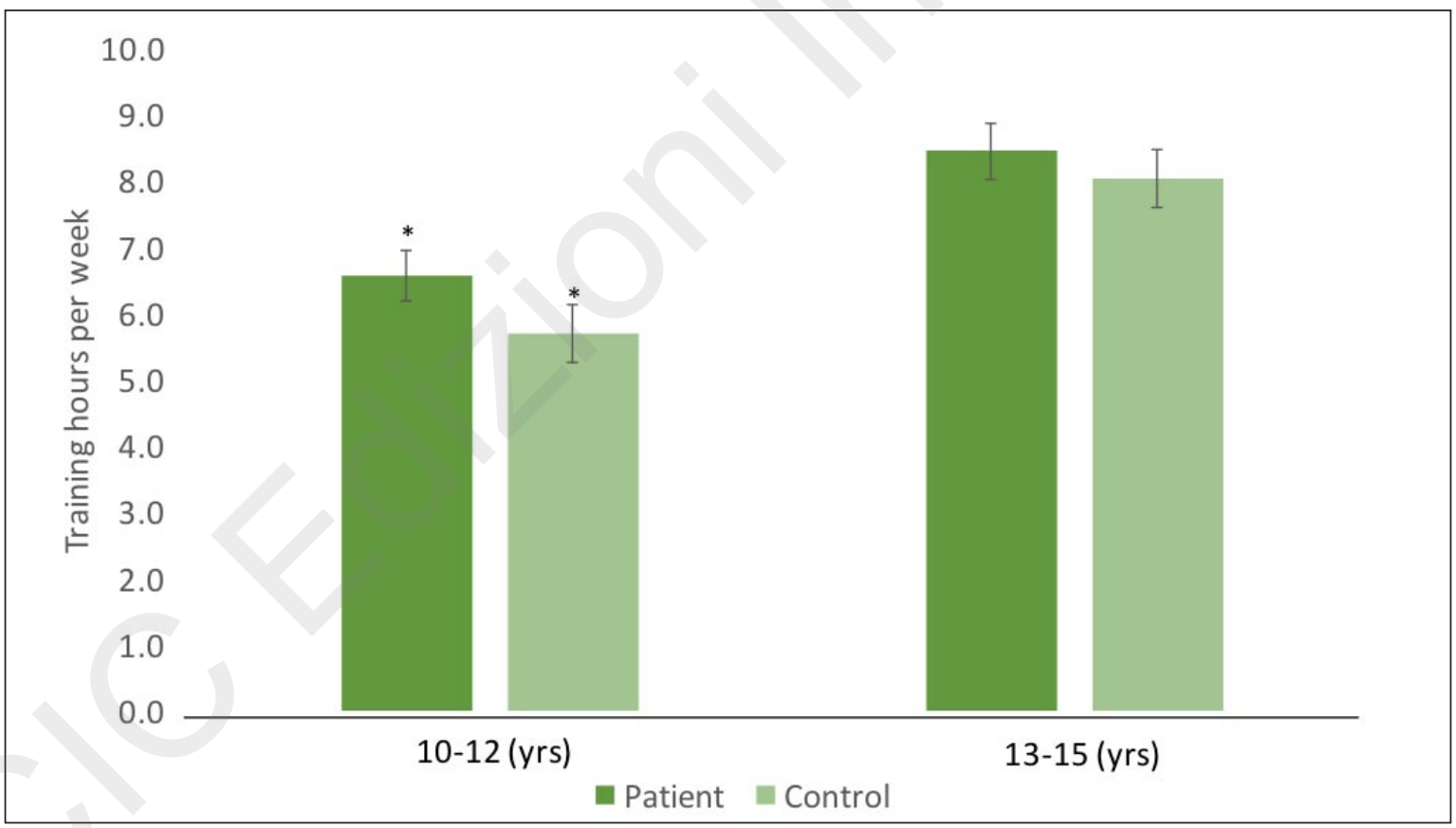

Figure 4. Differences in weekly training hours between groups (including SE bars). *Significance $p<0.05$.

athletic control group with no history of hip complaints.

The results of this study found that patients completed more hours of structured training between the ages of 10-12 years than the control group; no differences in training hours between the ages of 13-15 were reported between the groups. However, both patients and controls reported an increase in training hours during the ages of $13-15$ compared to the 10-
12 age bracket. Mackelvie et al. ${ }^{16}$ describe the two year time frame of $13-15$ years as the critical timeframe for peak bone velocity among adolescent boys, therefore a bony abnormality that develops prior to the age of 13 could then be amplified as training intensifies later in adolescence. Previous investigations in the area are limited although Johnson et al. ${ }^{10}$ reported on the incidences of cam deformity in former high-level youth soccer players ( $n=50,25$ males) and 
Table II. Differences in Hip ROM between patients and controls.

\begin{tabular}{|c|c|c|c|}
\hline Measure & Patients (Deg. \pm SD) & Controls (Deg. \pm SD) & $p$-value \\
\hline Flexion & $113 \pm 7$ & $117 \pm 5$ & $<0.001$ \\
\hline Abduction & $33 \pm 5$ & $44 \pm 8$ & $<0.001$ \\
\hline Internal rotation & $31 \pm 10$ & $53 \pm 10$ & $<0.001$ \\
\hline
\end{tabular}

a control group ( $n=50,25$ males), using AP radiographs. High level soccer was defined as engaging in three or more games or training sessions per week for at least 36 weeks of the year between the ages of 8-12 for girls and 10-14 for boys. The study did not show any evidence of greater incidence of cam deformity in males or females who had previously engaged in high levels of soccer during adolescence than those who did not. The differences in participant selection between that research and the current study could account for the differences in reported results. Recruiting asymptomatic individuals may underestimate the true nature of the problem.

The results of our study are in agreement with that of Tak et al. ${ }^{11}$ who suggested that the activity levels prior to the age of 12 were an important determining factor in the development of bony morphology in the hip among professional soccer players. Tak reported that the prevalence of pathological cam deformities was significantly higher in those that had engaged in training four or more times per week prior to the age of 12 years compared to those training less than four times per week before that age. In a prospective study design, Agricola et al. ${ }^{12}$ also reported cam deformity developments in young soccer players, which continued to develop until epiphyseal closure, following which the Authors observed a plateau in cam deformity development. The results of the current research indicate that bony deformities may begin prior to the age of 12 (while the growth plates are open) as result of heavy involvement in high impact sports. However, Agricola's findings would also point to the importance of the 13-15 years age range when the growth plates are still open, yet our results showed no significant difference in training volumes during these years. Agricola et al. report reduced internal rotation in athletes from the age of 13 with an alpha angle greater than $60^{\circ}$, which is consistent with our results showing not only reduced internal rotation in the patient group, but also significantly lower levels of flexion and abduction also. Reduced ROM observed in both the current study and the study carried out by Agricola et al. support the findings reported by Siebenrock et al. ${ }^{13}$ who compared high level basketball players, aged 9-25 years currently engaged in normal levels of training and competition to an age and gender matched non athletic control group, subcategorised into four distinct age groups; 9-12, 13-15, 16-21 and 22-25 years old. MRI images in the Siebenrock study indicated that overall athletes had significantly higher mean alpha angles along the anterosuperior quadrant of the femoral head compared to controls. The athlete group also had reduced internal rotation values at each age group compared to controls indicating a progressive loss of mechanical function over time among the athletic group. The 2225 years olds exhibited the greatest differences between the groups (12.4 degrees vs 27.8 degrees). The Authors concluded that the formation of a cam deformity is developmental, which may be exacerbated by high intensity loading of the proximal femur because of frequent exercise.

Although the difference in training volumes between 10-12 years of age was statistically significant between groups, the exact causative role of one additional hour of training/competition alone in the development of symptomatic FAl is not clear. Development of symptomatic $\mathrm{FAl}$ is undoubtedly multifactorial ${ }^{17}$, however the fact that one group of otherwise healthy athletes developed a chronic hip condition, while a matched control group who reported less training volume than the patient group did not, is an important finding of this study and warrants further investigation.

Previous research has identified sports such as soccer, baseball and ice hockey as sports commonly associated with $\mathrm{FAI}^{18-21}$. While the majority of sportsmen in both study groups included in this research were athletes participating in the Irish national sports of Hurling and Gaelic football; these sports are multidirectional, high intensity field sports ${ }^{22}$ similar to rugby, soccer and hockey (the other sports in this study) in terms of distances covered and movement patterns required ${ }^{23-25}$ and therefore likely represent the risk posed to other field sports athletes. Children may participate in organised and structured training for the Gaelic games as early as the "under-6" age category with their club. It is common in Gaelic games to play both Gaelic football and hurling concurrently (dual players) and to also play for teams at more than one age category in the same year leading to risks of overtraining. This is often further compounded by also competing for school and inter-county teams. There are no current regulations within the Gaelic Games Association (GAA) which limits the amount of weekly structured training a child can complete and so the demand on children to train/play for each team they are involved with can be substantial.

There are many benefits associated with participation in structured sports during adolescence including the 
development of motor skills ${ }^{26}$, social and cognitive developments ${ }^{27,28}$ as well as many increased health benefits. However, with the possible increased risk of hip injury further down the line, the balance between injury risk and health benefits must be carefully investigated. Further research is needed to determine which aspects of training and competition are most associated with the development of bony morphologies and to examine how children can acquire the skill sets and physical capacities required for sports participation while minimising any negative long term physical adaptations.

There are a number of limitations within the study design. Firstly, the control group was not clinically or radiographically assessed for FAI syndrome but was merely free from groin/hip pain or stiffness at the time of testing. However, we believe the fact that the control group, as well as being closely matched for age, height, body mass and sport type, was actively engaged in equivalent levels of competitive sport with no history or hip/groin pain or stiffness decreases the likelihood of an underlying hip pathology being present. Hip ROM was also reduced in the patient group compared to controls, demonstrating the distinct differences between groups with regard to mechanical function. As pathological hip conditions do not manifest themselves until later in the player pathway, athlete recall (although perceived as a limitation) is a methodological approach used within the subject area ${ }^{10,11}$. An advantage of the current research in relation to previously published literature includes the fact that the athletes included in the study were diagnosed with FAl which required treatment in comparison to previous research which included athletes with a deformity and not necessarily a hip pathology which effected participation or performance.

\section{Conclusions}

Significantly higher structured training and competition hours between the ages of 10 and 12 years were reported in athletes with FAl than a group of healthy matched controls. This study is the first to be conducted among athletes that required surgical intervention and highlights the need for extensive prospective research which assesses the links between training volume, duration, intensity and type with the development of bony morphologies which are symptomatic. If such research supports the links shown in this study it will serve to educate coaching staff involved with younger athletes and measures can be put in place to reduce risk.

\section{References}

1. Byrd JWT. Hip arthroscopy in the athlete. N Am J Sports Phys Ther. 2007;2(4):217-230.

2. Ellis HB, Briggs KK, Philippon MJ. Innovation in hip arthroscopy: is hip arthritis preventable in the athlete? $\mathrm{Br} \mathrm{J}$ Sports Med. 2011 Apr;45(4):253-258.
3. Philippon MJ, Maxwell RB, Johnston TL, Schenker M, Briggs KK. Clinical presentation of femoroacetabular impingement. Knee Surg Sports Traumatol Arthrosc. 2007 Aug;15(8):10411047.

4. Byrd JWT. Hip Arthroscopy in the Athlete. Oper Tech Sports Med. 2012 Dec;20(4):310-319.

5. Ganz R, Leunig M, Leunig-Ganz K, Harris WH. The etiology of osteoarthritis of the hip: An integrated mechanical concept. Clin Orthop Relat Res. 2008;466(2):264-272.

6. Ganz R, Parvizi J, Beck M, Leunig M, Nötzli H, Siebenrock KA Femoroacetabular Impingement: A Cause for Osteoarthritis of the Hip. Clin Orthop Relat Res. 2003;417:112-120.

7. Carton PF, Filan D. Labral cuff refixation in the hip: rationale and operative technique for preserving the chondrolabral interface for labral repair: a case series. J Hip Preserv Surg. 2018 Jan;5(1):78-87.

8. Philippon MJ, Faucet SC, Briggs KK. Arthroscopic hip labral repair. Arthrosc Tech. 2013;2(2):e73-76.

9. Philippon MJ, Briggs KK, Yen Y-M, Kuppersmith DA. Outcomes following hip arthroscopy for femoroacetabular impingement with associated chondrolabral dysfunction. Bone Joint J. 2009;91(1):16-23.

10. Johnson AC, Shaman MA, Ryan TG. Femoroacetabular impingement in former high-level youth soccer players. Am J Sports Med. 2012 Jul;40(6):1342-1346.

11. Tak I, Weir A, Langhout R, Waarsing JH, Stubbe J, Kerkhoffs $G$. The relationship between the frequency of football practice during skeletal growth and the presence of a cam deformity in adult elite football players. Br J Sports Med. 2015;49(9):630634.

12. Agricola R, Heijboer MP, Ginai AZ, Roels P, Zadpoor AA, Verhaar JAN, et al. A Cam Deformity Is Gradually Acquired During Skeletal Maturation in Adolescent and Young Male Soccer Players. A Prospective Study With Minimum 2-Year Followup. Am J Sports Med. 2014;42(4):798-806.

13. Siebenrock KA, Ferner F, Noble PC, Santore RF, Werlen S, Mamisch TC. The cam-type deformity of the proximal femur arises in childhood in response to vigorous sporting activity. Clin Orthop Relat Res. 2011;469(11):3229-3240.

14. Griffin DR, Dickenson EJ, O'Donnell J, Agricola R, Awan T, Beck M, et al. The Warwick Agreement on femoroacetabular impingement syndrome (FAl syndrome): an international consensus statement. Br J Sport Med. 2016 Oct 1;50(19):11691176.

15. Padulo J, Oliva F, Frizziero A, Maffulli N. Muscles, Ligaments and Tendons Journal - Basic principles and recommendations in clinical and field science research: 2016 update. MLTJ. 2016;6(1):1-5.

16. MacKelvie KJ, Khan KM, McKay HA. Is there a critical period for bone response to weight-bearing exercise in children and adolescents? A systematic review. Br J Sports Med. 2002;36(4):250-257.

17. Clohisy JC, Baca G, Beaulé PE, Kim Y-J, Larson CM, Millis $\mathrm{MB}$, et al. Descriptive epidemiology of femoroacetabular impingement: a North American cohort of patients undergoing surgery. Am J Sports Med. 2013;41(6):1348-1356.

18. Epstein DM, McHugh M, Yorio M, Neri B. Intra-articular hip injuries in National Hockey League players: a descriptive epidemiological study. Am J Sports Med. 2013;41(2):343-348.

19. Nepple JJ, Brophy RH, Matava MJ, Wright RW, Clohisy JC. Radiographic findings of femoroacetabular impingement in National Football League Combine athletes undergoing radiographs for previous hip or groin pain. Arthrosc J Arthrosc Relat Surg. 2012;28(10):1396-1403.

20. Philippon MJ, Ho CP, Briggs KK, Stull J, LaPrade RF. Prevalence of Increased Alpha Angles as a Measure of Cam-Type Femoroacetabular Impingement in Youth Ice Hockey Players. Am J Sports Med [Internet]. 2013 Apr 5;41(6):1357-1362. 
21. Fukushima K, Takahira N, Imai S, Yamazaki T, Kenmoku T, Uchiyama K, et al. Prevalence of radiological findings related to femoroacetabular impingement in professional baseball players in Japan. J Orthop Sci. 2016;21(6):821-825.

22. McIntyre MC. A comparison of the physiological profiles of elite Gaelic footballers, hurlers, and soccer players. Br J Sport Med [Internet]. 2005 Jul 1;39(7):437-439.

23. Malone S, Solan B, Collins K, Doran D. The Positional Match Running Performance of Elite Gaelic Football. J Strength Cond Res Strength Cond Assoc. 2016;8(3):2292-2298.

24. Malone S, Collins K, McRoberts A, Doran D. A comparison of work-rate displayed by elite and sub-elite hurlers during match play. Sciences (New York). 2013;22(3):255-256.
25. Malone S, Solan B, Collins KD, Doran DA. Positional Match Running Performance in Elite Gaelic Football. J Strength Cond Res. 2016;30(8):2292-2298.

26. Wrotniak BH, Epstein LH, Dorn JM, Jones KE, Kondilis VA The relationship between motor proficiency and physical activity in children. Pediatrics. 2006;118(6):e1758-1765.

27. Sibley BA, Etnier JL. The relationship between physical activity and cognition in children: a meta-analysis. Pediatr Exerc Sci. 2003;15(3):243-256.

28. Page RM, Tucker L. Psychosocial discomfort and exercise frequency: an epidemiological study of adolescents. Adolescence. 1994;29(113):183. 